\title{
Value of magnetic resonance spectroscopy in geriatric patients with cognitive impairment
}

\author{
Mamdouh Ali Kotb ${ }^{1,2^{*}}$ (D) Ahmed M. Kamal ${ }^{3,4}$, Nasser M. Aldossary ${ }^{5}$, Ayman A. Alsify ${ }^{5}$ and Yassmin M. Ahmed
}

\begin{abstract}
Background: Mild cognitive impairment is a transitional stage prior to dementia, and it is reported in depressed patients. Early diagnosis could predict the reversible etiologies and prevent further deterioration. Proton magnetic resonance spectroscopy has been used for early diagnosis and differential diagnosis of cognitive impairment.
\end{abstract}

Objective: We aimed to study the difference of hippocampal and frontal white matter metabolites between patients with Alzheimer's disease, mild cognitive impairment, and cognitive impairment associated with depression, and if those metabolites can differentiate between them.

Subjects and methods: Geriatric patients with cognitive impairment were recruited from neurology and psychiatry clinics. All subjects underwent comprehensive medical evaluations, neuropsychological testing, laboratory tests as well as brain MRI and ${ }^{1} \mathrm{H}$-MRS studies.

Results: The present study included 85 subjects. Patients with MCI and AD had lower hippocampal NAA and NAA/ $\mathrm{Cr}$ ratio than patients with depression and normal controls, while, frontal NAA and NAA/Cr ratio were lower in all patient's subgroups compared to normal control.

Conclusion: Hippocampal NAA and NAA/Cr ratio might help to differentiate between $\mathrm{MCl}$ and cognitive impairment associated with depression.

Keywords: Alzheimer's disease, Mild cognitive impairment, Spectroscopy, Geriatric patients

\section{Introduction}

Alzheimer's disease (AD) is the commonest cause of cognitive impairment in the geriatric population. It affects more than 35.6 million people living with dementia worldwide [1]. The transitional stage prior to dementia is mild cognitive impairment (MCI), with preserved activities of daily life [2], $20 \%$ of them develop dementia yearly [3]. MCI is reported in about $38 \%$ of depressed patients [4]. Furthermore, depression may be the early presenting feature of $\mathrm{AD}$ [5], and the diagnosis of depression can be difficult in the elderly [6]. The overall prevalence of depressive disorders among the geriatric

\footnotetext{
* Correspondence: mamdouhali19702001@gmail.com

${ }^{1}$ Neurology Department, College of Medicine, Prince Sattam bin Abdulaziz University, Alkharj, Kingdom of Saudi Arabia

${ }^{2}$ Neurology Department, Faculty of Medicine, Minia University, Minia, Egypt Full list of author information is available at the end of the article
}

population varies between 10 and $20 \%$, depending on the cultural situations $[7,8]$.

Several invasive neuroimaging tools such as PET or SPECT are useful to differentiate $\mathrm{MCI}$ from $\mathrm{AD}$ and healthy subjects $[9,10]$. However, these tools might not have a strong specificity for clinical diagnosis. Structural neuroimaging tools like MRI is used to evaluate brain volume and degree of tissue atrophy in geriatric patients with cognitive impairment $[11,12]$. But MRI usually misses the identification of early neuropathological changes. So, many new MRI techniques are currently used to evaluate the pathological processes underlying the development of cognitive impairment [13, 14]. Proton magnetic resonance spectroscopy $\left({ }^{1} \mathrm{H}-\mathrm{MRS}\right)$ is a recent technique that can, in vivo, evaluate human brain function, and it can measure the change of brain metabolite levels before structural changes. ${ }^{1} \mathrm{H}$-MRS has been used for early diagnosis and differential diagnosis of cognitive impairment [15]. 
Diagnosis of early signs of cognitive impairment is worth studying. It could predict the reversible etiologies and prevent further deterioration. In the elderly, cognitive deficit may be a sign of depression, $\mathrm{MCI}$, or AD. Differentiation between functional and organic causes of dementia is a cornerstone for early therapeutic intervention and prevention of further progression of the disorder. Our goals were (a) to study the difference of hippocampal, frontal white matter $\mathrm{N}$-acetylaspartate (NAA) concentrations, and $\mathrm{N}$-acetylaspartate/creatine $(\mathrm{NAA} / \mathrm{Cr}$ ) ratio between patients with $\mathrm{AD}, \mathrm{MCI}$, and cognitive impairment associated with depression, (b) to study if these metabolites could differentiate between MCI and cognitive impairment associated with depression.

\section{Subjects and methods}

This study was a prospective cross-sectional case-control study of geriatric patients with cognitive disturbances attending Prince Sattam Bin-Abdulaziz University Hospital, outpatient clinics. Elderly patients were recruited from neurology and psychiatry clinics during the period from March 2016 to February 2019. Age- and sex-matched healthy volunteers were included as a control group. The study was approved by local Institutional Review Board. A written informed consent was taken from the patients or their caregiver. All subjects underwent comprehensive medical evaluations, including medical history, neurological and psychiatric examinations, neuropsychological testing, laboratory tests as well as brain MRI. Subjects were excluded from the study if they had symptoms or signs of cerebral strokes, major neurological diseases that could affect cognitive function, major psychiatric disorders other than depression, comorbid dementia with depression, thyroid dysfunctions, seizures, alcohol or drug abuse or dependence, or any contraindication to MRI. Diagnosis of probable Alzheimer's disease was based on the criteria of the National Institute of Neurological and Communicative Disorders and Stroke and the Alzheimer's Disease and Related Disorders Association (NINCDS-ADRDA) group criteria [16]. Patients with mild to moderate severity according to the Clinical Dementia Rating Scale [17] were included. Patients with MCI must fulfill the criteria of Petersen et al. [18]: memory complaints, normal daily living activities, normal general cognitive function, and abnormal memory for age but no dementia. Memory complaints of the patients were corroborated by a family member. Diagnosis of depression was made in accordance with the Diagnostic and Statistical Manual of Mental Disorders fifth edition [19]. In order to improve the classification of $A D$, $\mathrm{MCI}$, and cognitive impairment associated with depression, we classified patients as follows: patients with clinical diagnosis (psychiatric interview, neuropsychiatric examination, and neuropsychological testing) of depression with memory domain improvement with repeated exposure, and with both control of encoding and retrieval cues were classified as cognitive impairment associated with depression. And patients with clinical diagnosis (psychiatric interview, neuropsychiatric examination, and neuropsychological testing) of $\mathrm{AD}$ or $\mathrm{MCI}$ with flat learning curve with repeated exposure, rapid forgetting, failure of recalling with cueing, and intrusions were classified as AD or MCI [20]. Patients with a confusing diagnosis were excluded from the study. All subjects were evaluated by The Geriatric Depression Scale (GDS) [21] and Montreal Cognitive Assessment Arabic version (MoCA) [22].

All subjects underwent MRI and ${ }^{1} \mathrm{H}-\mathrm{MRS}$ studies on a 1.5-T scanner (1.5 T Philips Gyroscan Intera, $2 \times 1.5 \mathrm{~T}$ Siemens Magnetom Vision, Best, Netherlands; $1.5 \mathrm{~T}$ Siemens Magnetom Sonata, Erlangen, Germany). Conventional MR images were obtained. ${ }^{1} \mathrm{H}$-MRS voxel of interest measuring $20 \times 10 \times 10 \mathrm{~mm}^{3}$ were defined in standard location in the left hippocampus. In a coronal slice, the voxel was started at the posterior margin of the amygdala and extended posteriorly for $20 \mathrm{~mm}$ (Fig. 1). The studied part of the hippocampus included both grey and white matter and the most posterior portion of the amygdala. The second location was the left frontal white matter, the voxel size was $20 \times 20 \times$ $20 \mathrm{~mm}^{3}$, and the voxel was placed in normal-appearing left frontal white matter (Fig. 2).

\section{Statistical analysis}

The data were analyzed using the Statistical Package for the Social Sciences (SPSS) 13.0. Descriptive statistics were calculated. Difference between genders was evaluated by nonparametric chi-squared test. Group differences in age, GDS, MoCA, and metabolite concentrations were evaluated by one-way analysis of variance (ANOVA), Bonferroni post hoc analysis was used. Pearson's correlation coefficient $(r)$ was employed to analyze the association between the different variables. Values of $P<0.05$ were considered to be statistically significant.

\section{Results}

The present study included 73 subjects without age and gender significant differences between subjects' subgroups. Patients with $\mathrm{AD}$ and $\mathrm{MCI}$ had significantly lower hippocampal NAA than patients with cognitive impairment associated with depression and normal controls. Similarly, patients with AD and MCI had significantly lower hippocampal NAA/Cr ratio than patients with cognitive impairment associated with depression and normal controls. Hippocampal and frontal creatine levels were constantly stable among patients' subgroups.

Frontal NAA was significantly lower in patients with $\mathrm{AD}$ than patients with MCI and normal controls, at the same time, patients with cognitive impairment associated with depression and patients with MCI had significantly lower frontal NAA than normal controls. 


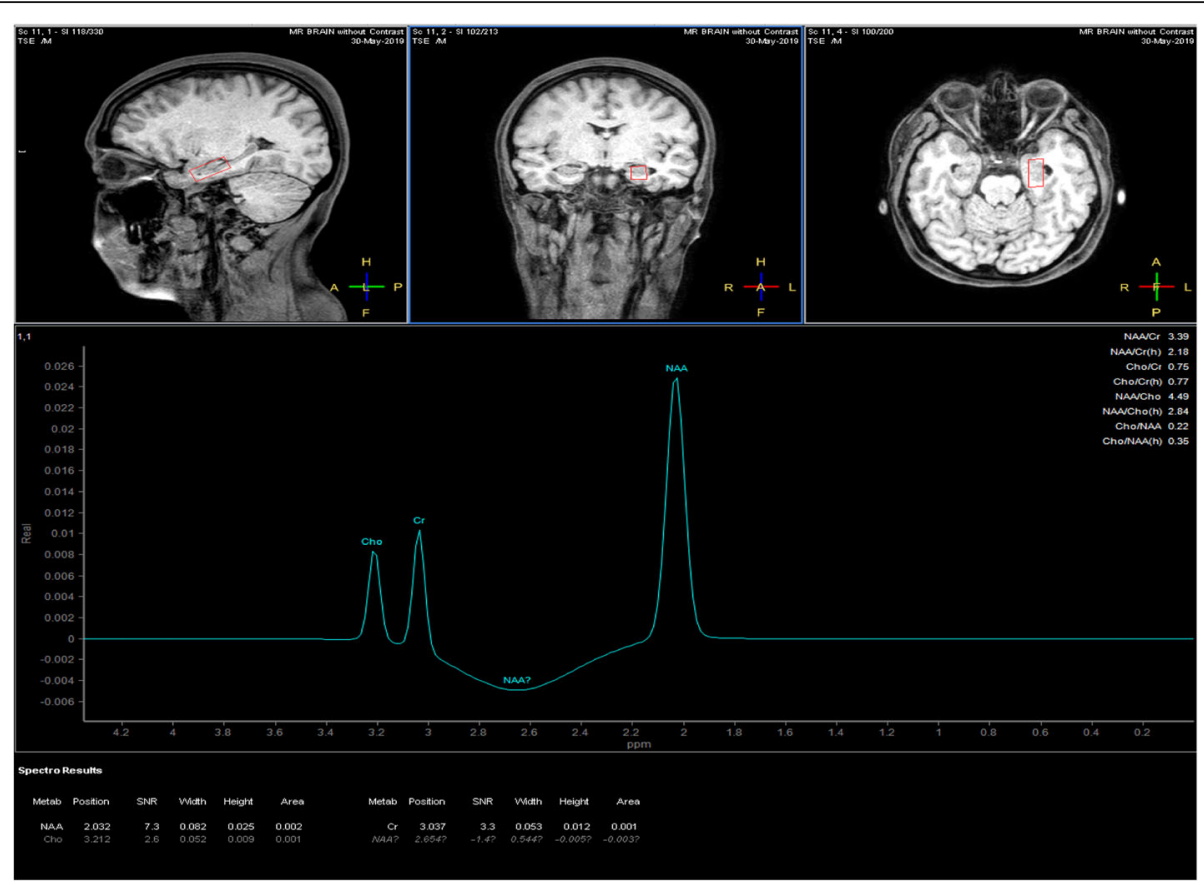

Fig. 1 The location of MRS voxel with a representative spectrum in the left hippocampus

Patients with $\mathrm{AD}$ and patients with cognitive impairment associated with depression had significantly lower frontal $\mathrm{NAA} / \mathrm{Cr}$ ratio than patients with $\mathrm{MCI}$ and normal controls. On the other hand, frontal $\mathrm{NAA} / \mathrm{Cr}$ ratio was significantly lower in patients with MCI than normal controls. The highest GDS score was reported among patients with cognitive impairment associated with depression. Regarding MoCA scores, patients' subgroups had significantly lower MoCA scores compared with normal controls, within patients' subgroups; patients with $\mathrm{AD}$ had the lowest MoCA scores (Table 1).

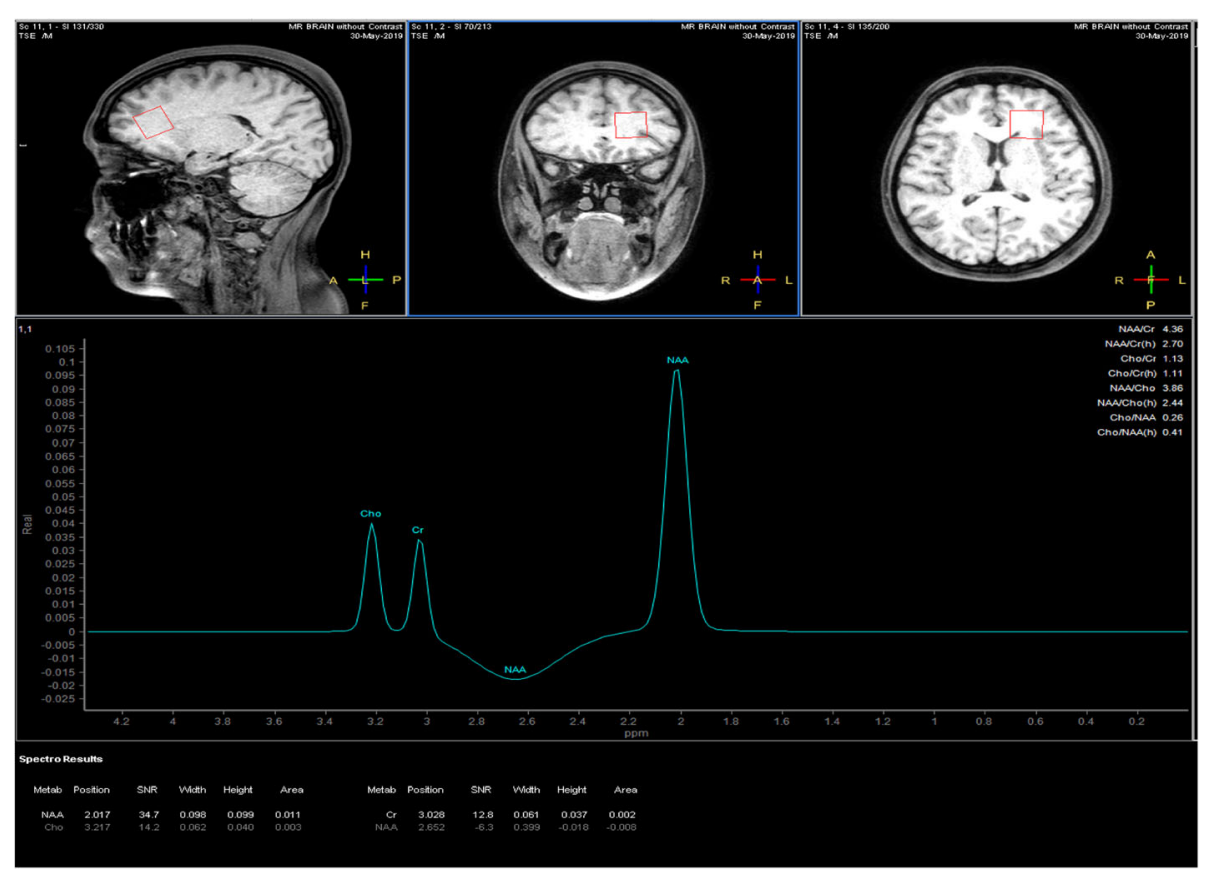

Fig. 2 The location of MRS voxel with a representative spectrum in the left frontal white matter 


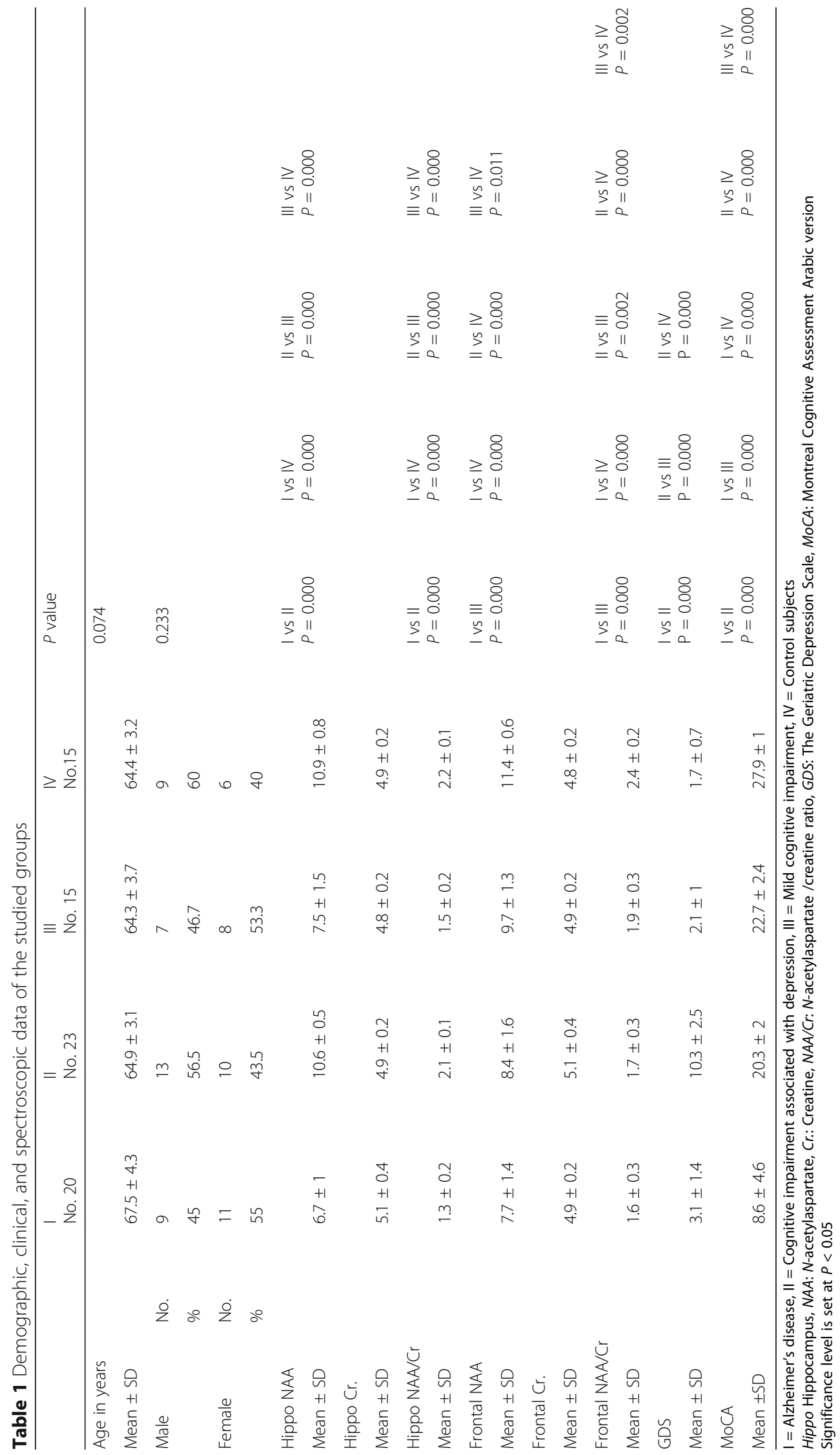


Patients with AD showed significant positive correlation between MoCA and both hippocampal NAA and hippocampal NAA/Cr ratio. No other significant correlations were reported between clinical data and the radiological parameters in this group of patients (Table 2). On the other hand, patients with cognitive impairment associated with depression showed a significant negative correlation between GDS in one arm and hippocampal NAA, hippocampal NAA/Cr ratio, frontal NAA, and frontal NAA/Cr ratio in the other arm (Table 3).

Patients with MCI had a positive significant correlation between MoCA and hippocampal NAA and hippocampal NAA/Cr ratio (Table 4). While normal controls showed no significant correlation between the clinical and the spectroscopic data (Table 5).

\section{Discussion}

The present study showed that hippocampal NAA level and $\mathrm{NAA} / \mathrm{Cr}$ ratio could differentiate patients with $\mathrm{MCI}$ from elderly depressed patients with cognitive impairment.

Patients with $\mathrm{AD}$ and patients with $\mathrm{MCI}$ had significantly lower hippocampal NAA and NAA/Cr ratio than other groups. In accordance with our results, Watanabe et al. [23] reported an intermediate hippocampal NAA level in patients with MCI that was lower than normal control but higher than AD patients. The meta-analysis study of Tumati et al. [24] revealed a lower hippocampal NAA level in MCI group compared with healthy controls. In partial contradiction to our results, Jessen et al. [25] reported a higher medial temporal lobe NAA concentration in $\mathrm{MCI}$ patients than in patients with $\mathrm{AD}$, but no difference was observed between MCI and healthy subjects. Another study reported a lower hippocampal

Table 2 Correlations between age, clinical, and spectroscopic data in patients with $A D$

\begin{tabular}{|c|c|c|c|c|}
\hline & & Age in years & GDS & MoCA \\
\hline \multirow[t]{2}{*}{ Hippo NAA } & Pearson correlation & .184 & -.019 & .710 \\
\hline & Significance & .438 & .937 & .000 \\
\hline \multirow[t]{2}{*}{ Hippo Cr. } & Pearson correlation & -.351 & -.319 & .095 \\
\hline & Significance & .129 & .170 & .689 \\
\hline \multirow[t]{2}{*}{ Hippo NAA/Cr } & Pearson correlation & .359 & .143 & .599 \\
\hline & Significance & .120 & .548 & .005 \\
\hline \multirow[t]{2}{*}{ Frontal NAA } & Pearson correlation & .195 & .060 & .325 \\
\hline & Significance & .411 & .802 & .162 \\
\hline \multirow[t]{2}{*}{ Frontal Cr. } & Pearson correlation & -.031 & .140 & -.010 \\
\hline & Significance & .898 & .556 & .968 \\
\hline \multirow[t]{2}{*}{ Frontal NAA/Cr } & Pearson correlation & .204 & .018 & .317 \\
\hline & Significance & .388 & .940 & .173 \\
\hline \multicolumn{5}{|c|}{$\begin{array}{l}\text { Hippo: Hippocampus, NAA: } N \text {-acetylaspartate, } C r .: \text { Creatine, } N A A / C r: N- \\
\text { acetylaspartate /creatine ratio, GDS: The Geriatric Depression Scale, } M o C A \text { : } \\
\text { Montreal Cognitive Assessment Arabic version } \\
\text { Significance level is set at } P<0.05\end{array}$} \\
\hline
\end{tabular}

Table 3 Correlations between age, clinical, and spectroscopic data in patients with cognitive impairment associated with depression

\begin{tabular}{lllll}
\hline & & Age in years & GDS & MoCA \\
\hline Hippo NAA & Pearson correlation & -.051 & -.598 & -.219 \\
& Significance & .817 & .003 & .315 \\
Hippo Cr. & Pearson correlation & .352 & -.187 & .246 \\
& Significance & .100 & .392 & .258 \\
Hippo NAA/Cr & Pearson correlation & -.292 & -.450 & -.393 \\
& Significance & .176 & .031 & .063 \\
Frontal NAA & Pearson correlation & -.123 & -.864 & -.241 \\
& Significance & .575 & .000 & .268 \\
Frontal Cr. & Pearson correlation & .221 & -.155 & .079 \\
& Significance & .312 & .480 & .718 \\
Frontal NAA/Cr & Pearson correlation & -.223 & -.816 & -.289 \\
& Significance & .306 & .000 & .181 \\
\hline
\end{tabular}

Hippo: Hippocampus, NAA: $\mathrm{N}$-acetylaspartate, Cr.: Creatine, NAA/Cr: $N$ acetylaspartate /creatine ratio, GDS: The Geriatric Depression Scale, MoCA: Montreal Cognitive Assessment Arabic version

Significance level is set at $P<0.05$

NAA in patients with AD compared to patients with $\mathrm{MCI}$ and healthy control and a tendency towards a significant difference in NAA between $\mathrm{MCI}$ and healthy controls [26]. However, no difference was observed between $\mathrm{MCI}, \mathrm{AD}$, and healthy subjects in the study of Rupsingh et al. [27]. Previous studies reported also a significant reduction of NAA levels in patients with $\mathrm{AD}$ compared with age-matched normal subjects $[28,29]$. Many previous studies did not find differences in hippocampal NAA in patients with depression compared with healthy subjects [30-32]. Although Venkatraman et al.

Table 4 Correlations between age, clinical, and spectroscopic data in patients with mild cognitive impairment

\begin{tabular}{lllll}
\hline & & Age in years & GDS & MoCA \\
\hline Hippo NAA & Pearson correlation & .265 & .226 & .568 \\
& Significance & .341 & .418 & .027 \\
Hippo Cr. & Pearson correlation & .307 & .369 & .411 \\
& Significance & .266 & .176 & .128 \\
Hippo NAA/Cr & Pearson correlation & .241 & .151 & .576 \\
& Significance & .387 & .592 & .024 \\
Frontal NAA & Pearson correlation & .164 & .269 & .235 \\
& Significance & .560 & .331 & .399 \\
Frontal Cr. & Pearson correlation & -.273 & .175 & .499 \\
& Significance & .325 & .532 & .058 \\
Frontal NAA/Cr & Pearson correlation & .262 & .220 & .112 \\
& Significance & .346 & .430 & .690 \\
\hline
\end{tabular}

Hippo: Hippocampus, NAA: $\mathrm{N}$-acetylaspartate, Cr.: Creatine, NAA/Cr: $N$ acetylaspartate /creatine ratio, GDS: The Geriatric Depression Scale, MoCA: Montreal Cognitive Assessment Arabic version

Significance level is set at $P<0.05$ 
Table 5 Correlations between age, clinical, and spectroscopic data in normal controls

\begin{tabular}{lllll}
\hline & & Age in years & GDS & MoCA \\
\hline Hippo NAA & Pearson correlation & -.251 & .033 & -.102 \\
& Significance & .366 & .907 & .717 \\
Hippo Cr. & Pearson correlation & -.233 & .068 & .105 \\
& Significance & .404 & .810 & .711 \\
Hippo NAA/Cr & Pearson correlation & -.105 & -.009 & -.148 \\
& Significance & .709 & .975 & .599 \\
Frontal NAA & Pearson correlation & .123 & -.293 & .084 \\
& Significance & .662 & .289 & .767 \\
Frontal Cr. & Pearson correlation & .375 & -.105 & .297 \\
& Significance & .168 & .710 & .282 \\
Frontal NAA/Cr & Pearson correlation & -.115 & -.138 & -.094 \\
& Significance & .684 & .623 & .738 \\
\hline
\end{tabular}

Hippo: Hippocampus, NAA: $\mathrm{N}$-acetylaspartate, $\mathrm{Cr}$.: Creatine, NAA/Cr: $\mathrm{N}$ acetylaspartate /creatine ratio, GDS: The Geriatric Depression Scale, MoCA: Montreal Cognitive Assessment Arabic version

Significance level is set at $P<0.05$

[33] reported an increased left medial temporal lobe NAA in late-life depression, without any change in the right one.

It was reported that hippocampal $\mathrm{NAA} / \mathrm{Cr}$ ratio decreased significantly in $\mathrm{AD}$ patients, but not in patients with MCI, compared with healthy control [27]. In other studies, the hippocampal NAA/Cr ratio was decreased in patients with $\mathrm{AD}[25,27]$ and MCI compared to healthy subjects $[15,24,29]$. A lower $\mathrm{NAA} / \mathrm{Cr}$ ratio was reported in the left hippocampus in $\mathrm{AD}$ and $\mathrm{MCI}$ patients $[15,34]$, and both hippocampi in AD patients [35] compared with healthy subjects.

In patients with major depressive disorder, the hippocampal NAA/Cr ratio did not differ from the control group [31]. However, in patients with post-stroke depression, the ratio decreased in both hippocampi [36], it also decreased in the left hippocampus in patients with first-episode major depressive disorder [37].

Hippocampal complex plays an important role in memory [38]. The initial pathological changes of $\mathrm{AD}$ first occur in the entorhinal cortex, then the hippocampus, and spread to other areas [39]. Structurally, hippocampal atrophy occurs early in Alzheimer's disease [40]. The most affected site in patients with MCI is the anterior hippocampal formation [41]. Moreover, marked cortical atrophy in the temporal region including the hippocampus had been reported in MCI patients [42]. Patients with depression had been reported to have hippocampal-dependent memory deficits that were exacerbated with the progression of depression [32]. Hypothalamic pituitary dysfunction occurs in patients with depression, which could affect the hippocampus with subsequent reduction of hippocampal volume [43]. Hippocampal volume changes might explain the metabolic abnormalities reported in previous studies.

Frontal NAA and NAA/Cr ratio were significantly lower in all patient groups than normal controls. A previous study reported lower frontal NAA in patients with AD than control subjects [44]. Similarly, the left prefrontal cortex NAA was decreased in patients with $\mathrm{MCI}$ compared to healthy control [45]. Other study reported no difference between patients with $\mathrm{MCI}, \mathrm{AD}$, and healthy control regarding the frontal NAA level [46].

Lower frontal NAA was reported in the frontal white matter in patients with late-life depression [47]. However, no significant difference was reported in patients with MDD in other studies [30, 48]. Olvera et al. [49], studied patients with MDD and found decreased NAA level in right medial prefrontal cortex, and a trend towards the decreased level in the left dorsolateral prefrontal gray matter and right dorsolateral prefrontal white matter.

For $\mathrm{AD}$ relative to healthy subjects, there was a strong tendency toward a statistically significant reduced NAA/ $\mathrm{Cr}$ ratio in the left frontal region [50]. In patients with $\mathrm{MCI}, \mathrm{NAA} / \mathrm{Cr}$ ratio was mildly reduced but it dropped as $\mathrm{MCI}$ progressed to $\mathrm{AD}$, in addition, a lower $\mathrm{NAA} / \mathrm{Cr}$ could predict progression to $\mathrm{AD}[51,52]$.

NAA/Cr was significantly lower in bilateral dorsolateral prefrontal white matter in MDD patients than healthy control $[53,54]$. NAA/Cr was reduced also in the right prefrontal cortex in moderate MDD patients but it did not change in patients with mild MDD [48]; however, other study did not show significant changes on NAA/Cr ratio in bilateral ventral prefrontal white matter in patients with major depressive disorder [55]. In the study of Chen et al. (2009), patients with late-life major depressive disorder had a significantly lower $\mathrm{NAA} / \mathrm{Cr}$ ratio in the frontal white matter than healthy subjects. A lower NAA/Cr ratio might indicate a neurodegenerative process in frontal white matter in late-life depression $[47,56]$.

The amygdala and the prefrontal cortex interconnected with many areas and play a major role in mood regulation [57]. Neuronal or glial loss in the frontal cortex and connectivity impairment between left frontal and limbic structure have been reported in late-life depression. These changes support theories of frontolimbic dysregulation in depression $[33,58,59]$. Accordingly, the metabolic changes reported in the hippocampus might be related to decreased frontal lobe inhibition of the amygdala.

Frontal lobe atrophic changes and hyperactivation had been reported in patients with MCI and AD [60-68]. However, frontal cortex hypoactivation was reported in MCI patients with prominent cognitive decline [65, 69- 
71]. Changes in frontal lobe activation in patients with MCI might be a compensatory mechanism to maintain normal cognitive ability [72].

In the present study, hippocampal NAA and NAA/ $\mathrm{Cr}$ ratio correlated positively with cognitive ability (as measured by MoCA) of patients with $\mathrm{AD}$ and patients with MCI. A previous study reported a significant correlation between NAA/Cr ratio and cognitive testing in Alzheimer's disease [29]. NAA/Cr ratio in the medial temporal lobe correlated with Mini-Mental State Examination (MMSE) and the cognitive part of the Alzheimer Disease Assessment Scale scores [73]. NAA/Cr ratio correlated also with verbal memory testing and general cognition [74]. Hippocampal metabolic concentration had strong correlations with MMSE and Revised Wechsler Memory Scale in patients with AD [23]. A strong relation was also reported between hippocampal NAA and cognitive tests, specifically the memory subtests of the Consortium to Establish a Registry for Alzheimer's Disease(CERAD) neuropsychological battery in patients with $\mathrm{AD}[26,27]$. Moreover, low gray matter NAA level was related to poor performance on recognition memory tests [75].

Levels of NAA in medial temporal lobe had been reported to have a positive association with verbal memory ability both in MCI and AD [26, 76]. A significant positive correlation was reported between hippocampal NAA, hippocampal NAA/Cr ratio, and MMSE in patients with MCI $[26,27]$. Hippocampal NAA was clearly related to delayed recall of a learned word list and the delayed praxis subtests of the CERDA battery [26]. It had been reported that right and left hippocampal NAA levels correlated positively with subtests of Wechsler Memory Scale-Revised, and the correlation was more prominent for the left hippocampus than the right hippocampus, which might suggest the importance of the left hippocampus in episodic memory function, moreover, NAA levels might reflect memory performance of patients with $\mathrm{MCI}$ and $\mathrm{AD}$ [76].

In depressed patients, we observed a negative correlation between depression scores and hippocampal and frontal metabolite levels. A significant positive correlation was observed between Beck Depression Inventory (BDI) and hippocampal NAA but not with $\mathrm{NAA} / \mathrm{Cr}$ ratio [31]. A significant correlation was reported also between the memory quotient and NAA/ $\mathrm{Cr}$ ratio in bilateral dorsolateral prefrontal white matters. Correlations with statistical significance were determined between $\mathrm{NAA} / \mathrm{Cr}$ in the left dorsolateral prefrontal white matter and visual regeneration, and associative learning. The right dorsolateral prefrontal white matter $\mathrm{NAA} / \mathrm{Cr}$ ratio correlated significantly with personal experience, visual recognition, and associative learning in depressed patients [54].
The point of strength in this study is that, although, $\mathrm{MCI}$ and depression are common in the geriatric population and differentiation between them is a challenging issue. Our study showed that MRS could help in solving this challenging situation. Our study was limited by some factors including, the relatively small number of patients that might be explained by the few numbers of elderly patients who fulfilled the criteria of inclusion in the study, and MRS is a costly procedure. Also, a considerable number of patients could not tolerate or refused to do an MRI brain. Other brain areas, as cingulate gyrus, and occipital lobe, were not studied to avoid too long time of brain scan. We recommend further study that includes other brain areas which might improve the classification of cognitive impairment in geriatric population.

\section{Conclusions}

In conclusion, patients with $\mathrm{MCI}$ and $\mathrm{AD}$ had lower hippocampal NAA and NAA/Cr ratio than patients with depression and normal controls, while, frontal NAA and $\mathrm{NAA} / \mathrm{Cr}$ ratio were lower in all patient's subgroups compared with normal control. Hippocampal NAA and $\mathrm{NAA} / \mathrm{Cr}$ ratio might help to differentiate between $\mathrm{MCI}$ and cognitive impairment associated with depression.

\begin{abstract}
Acknowledgements
Not applicable.

\section{Authors' contributions}

All authors contributed to the research idea. MAK, AMK, and AAA contributed to the data collection. MAK, AMK, and AAA analyzed the data and along with NMD who interpreted the data. Further, MAK and YMA completed the first draft of the article. All authors were involved in drafting the article or revising it critically for important intellectual content, and all authors approved the final version to be published.
\end{abstract}

Funding

There is no source of funding for this research.

Availability of data and materials

All datasets generated and analyzed during the current study are not publicly available but are available by reasonable request from the corresponding author.

\section{Ethics approval and consent to participate}

The study was approved by the Institutional Review Board of College of Medicine, Prince Sattam Bin Abdulaziz University, KSA on 4 January 2016. A written consent was taken from all of the participants or their caregiver after explaining the details, benefits, and risks to them.

Consent for publication

Not applicable.

Competing interests

The authors declare that they have no competing interests.

\section{Author details}

${ }^{1}$ Neurology Department, College of Medicine, Prince Sattam bin Abdulaziz University, Alkharj, Kingdom of Saudi Arabia. ${ }^{2}$ Neurology Department, Faculty of Medicine, Minia University, Minia, Egypt. ${ }^{3}$ Psychiatry Department, College of Medicine, Prince Sattam bin Abdulaziz University, Alkharj, Kingdom of Saudi Arabia. ${ }^{4}$ Psychiatry Department, Faculty of Medicine, Minia University, 
Minia, Egypt. ${ }^{5}$ Radiology Department, College of Medicine, Prince Sattam bin Abdulaziz University, Alkharj, Kingdom of Saudi Arabia. ${ }^{6}$ Medical student, Faculty of Medicine, Minia University, Minia, Egypt.

\section{Received: 13 June 2019 Accepted: 6 January 2020}

Published online: 14 January 2020

\section{References}

1. Chan KY, Wang W, Wu JJ, Liu L, Theodoratou E, Car J, et al. Epidemiology of Alzheimer's disease and other forms of dementia in China, 1990-2010: a systematic review and analysis. Lancet. 2013;381(9882):2016-23.

2. Lin JS, O'Connor E, Rossom RC, Perdue LA, Eckstrom E. Screening for cognitive impairment in older adults: a systematic review for the US Preventive Services Task Force. Ann Internal Med. 2013;159(9):601-12.

3. Etgen T, Sander D, Bickel H, Förstl H. Mild cognitive impairment and dementia: the importance of modifiable risk factors. Dtsch Arztebl Int. 2011; 108(44):743.

4. Reischies FM, Neu P. Comorbidity of mild cognitive disorder and depression-a neuropsychological analysis. Eur Arch Psychiatry Clin Neurosci. 2000:250(4):186-93.

5. Evans M, Mottram P. Diagnosis of depression in elderly patients. Adv Psychiatr Treatment. 2000;6(1):49-56.

6. Gottfries CG. Late life depression. Eur Arch Psychiatry Clin Neurosci. 2001; 251(Suppl 2):I157-61.

7. Rangaswamy S. World Health Report: Mental health: new understanding new hope. Geneva: The World Health Organization; 2001.

8. Wig NN. World health day 2001. Ind J Psychiatry. 2001;43(1):1.

9. Chetelat G, Desgranges B, De La Sayette V, Viader F, Eustache F, Baron J-C. Mild cognitive impairment: can FDG-PET predict who is to rapidly convert to Alzheimer's disease? Neurology. 2003;60(8):1374-7.

10. Drzezga A, Lautenschlager N, Siebner H, Riemenschneider M, Willoch F, Minoshima S, et al. Cerebral metabolic changes accompanying conversion of mild cognitive impairment into Alzheimer's disease: a PET follow-up study. Eur J Nucl Med Mol Imaging. 2003;30(8):1104-13.

11. Chincarini A, Bosco P, Calvini P, Gemme G, Esposito M, Olivieri C, et al. Loca MRI analysis approach in the diagnosis of early and prodromal Alzheimer's disease. Neuroimage. 2011:58(2):469-80.

12. Liu Y, Paajanen T, Zhang Y, Westman E, Wahlund L-O, Simmons A, et al. Analysis of regional MRI volumes and thicknesses as predictors of conversion from mild cognitive impairment to Alzheimer's disease. Neurobiol Aging. 2010;31(8):1375-85.

13. O'brien J. Role of imaging techniques in the diagnosis of dementia. $\mathrm{Br} J$ Radiol. 2007:80(special_issue_2):S71-S7.

14. Li T-Q, Wahlund L-O. The search for neuroimaging biomarkers of Alzheimer's disease with advanced MRI techniques. Acta Radiologica. 2011 52(2):211-22.

15. Targosz-Gajniak MG, Siuda JS, Wicher MM, Banasik TJ, Bujak MA, AugusciakDuma AM, et al. Magnetic resonance spectroscopy as a predictor of conversion of mild cognitive impairment to dementia. J Neurol Sci. 2013; 335(1-2):58-63.

16. McKhann G, Drachman D, Folstein M, Katzman R, Price D, Stadlan EM. Clinical diagnosis of Alzheimer's disease: report of the NINCDS-ADRDA Work Group* under the auspices of Department of Health and Human Services Task Force on Alzheimer's Disease. Neurology. 1984;34(7):939.

17. Morris JC. The Clinical Dementia Rating (CDR): current version and scoring rules. Neurology. 1993

18. Petersen RC, Smith GE, Waring SC, Ivnik RJ, Tangalos EG, Kokmen E. Mild cognitive impairment: clinical characterization and outcome. Arch Neurol. 1999:56(3):303-8.

19. Edition F. Diagnostic and statistical manual of mental disorders. Am Psychiatric Assoc. 2013.

20. Leyhe T, Reynolds CF III, Melcher T, Linnemann C, Klöppel S, Blennow K, et al. A common challenge in older adults: Classification, overlap, and therapy of depression and dementia. Alzheimers Dement. 2017;13(1):59-71.

21. Greenberg SA. The geriatric depression scale (GDS). Best Pract Nursing Care Older Adults. 2012:4(1):1-2

22. Rahman TTA, El Gaafary MM. Montreal cognitive assessment Arabic version: reliability and validity prevalence of mild cognitive impairment among elderly attending geriatric clubs in Cairo. Geriatr Gerontol Int. 2009;9(1):54-61.

23. Watanabe T, Shiino A, Akiguchi I. Absolute quantification in proton magnetic resonance spectroscopy is useful to differentiate amnesic mild cognitive impairment from Alzheimer's disease and healthy aging. Dement Geriatr Cogn Disord. 2010;30(1):71-7.

24. Tumati S, Martens S, Aleman A. Magnetic resonance spectroscopy in mild cognitive impairment: systematic review and meta-analysis. Neurosci Biobehav Rev. 2013;37(10):2571-86.

25. Jessen F, Gür O, Block W, Ende G, Frölich L, Hammen T, et al. A multicenter $1 \mathrm{H}-\mathrm{MRS}$ study of the medial temporal lobe in AD and MCI. Neurology. 2009; 72(20):1735-40.

26. Foy CM, Daly EM, Glover A, O'Gorman R, Simmons A, Murphy DG, et al. Hippocampal proton MR spectroscopy in early Alzheimer's disease and mild cognitive impairment. Brain Topogr. 2011;24(3-4):316-22.

27. Rupsingh R, Borrie M, Smith M, Wells J, Bartha R. Reduced hippocampal glutamate in Alzheimer disease. Neurobiol Aging. 2011;32(5):802-10.

28. Graff-Radford J, Kantarci K. Magnetic resonance spectroscopy in Alzheimer's disease. Neuropsychiatric Dis Treat. 2013;9:687.

29. Ackl N, Ising M, Schreiber YA, Atiya M, Sonntag A, Auer DP. Hippocampal metabolic abnormalities in mild cognitive impairment and Alzheimer's disease. Neurosci Lett. 2005;384(1-2):23-8

30. Yildiz-Yesiloglu A, Ankerst DP. Review of $1 \mathrm{H}$ magnetic resonance spectroscopy findings in major depressive disorder: a meta-analysis. Psychiatry Res. 2006:147(1):1-25.

31. Block W, Träber F, von Widdern O, Metten M, Schild H, Maier W, et al. Proton MR spectroscopy of the hippocampus at $3 \mathrm{~T}$ in patients with unipolar major depressive disorder: correlates and predictors of treatment response. Int J Neuropsychopharmacol. 2009;12(3):415-22.

32. Milne A, MacQueen GM, Yucel K, Soreni N, Hall GB. Hippocampal metabolic abnormalities at first onset and with recurrent episodes of a major depressive disorder: a proton magnetic resonance spectroscopy study. Neuroimage. 2009;47(1):36-41.

33. Venkatraman TN, Krishnan RR, Steffens DC, Song AW, Taylor WD. Biochemical abnormalities of the medial temporal lobe and medial prefrontal cortex in late-life depression. Psychiatry Res. 2009; 172(1):49-54

34. Dixon RM, Bradley KM, Budge MM, Styles P, Smith AD. Longitudinal quantitative proton magnetic resonance spectroscopy of the hippocampus in Alzheimer's disease. Brain. 2002;125(10):2332-41.

35. Block W, Jessen F, Träber F, Flacke S, Manka C, Lamerichs R, et al. Regional $\mathrm{N}$-acetylaspartate reduction in the hippocampus detected with fast proton magnetic resonance spectroscopic imaging in patients with Alzheimer disease. Arch Neurol. 2002;59(5):828-34.

36. Huang Y, Chen W, Li Y, Wu X, Shi X, Geng D. Effects of antidepressant treatment on $\mathrm{N}$-acetyl aspartate and choline levels in the hippocampus and thalami of post-stroke depression patients: A study using $1 \mathrm{H}$ magnetic resonance spectroscopy. Psychiatry Res. 2010;182(1):48-52.

37. Xiancang $M$, Sun $Y$, Gao C, Sun Q, Ding H, Bolang Y. 1H-MRS in frontal lobe and hippocampus of patients with first episode major depression. J Xi'an Jiaotong Univ (Medical Sciences). 1981;(02).

38. Golomb J, de Leon MJ, Kluger A, George AE, Tarshish C, Ferris SH. Hippocampal atrophy in normal aging. An association with recent memory impairment. Arch Neurol. 1993;50(9):967-73.

39. Braak H, Braak E. Neuropathological stageing of Alzheimer-related changes. Acta Neuropathologica. 1991;82(4):239-59.

40. Convit A, De Leon M, Golomb J, George A, Tarshish C, Bobinski M, et al. Hippocampal atrophy in early Alzheimer's disease: anatomic specificity and validation. Psychiatr Q. 1993:64(4):371-87.

41. Petersen $R C$, Jack $C$, Xu Y-C, Waring S, O'brien P, Smith G, et al. Memory and MRI-based hippocampal volumes in aging and $A D$. Neurology. 2000;54(3):581

42. Seo SW, Im K, Lee J-M, Kim Y-H, Kim ST, Kim SY, et al. Cortical thickness in single-versus multiple-domain amnestic mild cognitive impairment. Neuroimage. 2007:36(2):289-97.

43. McEwen BS. Mood disorders and allostatic load. Biol Psychiatry. 2003;54(3):200-7.

44. Valenzuela MJ, Sachdev P. Magnetic resonance spectroscopy in AD. Neurology. 2001:56(5):592-8.

45. Li X, Shao X, Wang N, Wang T, Chen G, Zhou H. Correlation of auditory event-related potentials and magnetic resonance spectroscopy measures in mild cognitive impairment. Brain Res. 2010;1346:204-12.

46. Siger M, Schuff N, Zhu X, Miller BL, Weiner MW. Regional myo-inositol concentration in mild cognitive impairment Using $1 \mathrm{H}$ magnetic resonance spectroscopic imaging. Alzheimer Dis Assoc Disord. 2009; 23(1):57. 
47. Chen C-S, Chiang I-C, Li C-W, Lin W-C, Lu C-Y, Hsieh T-J, et al. Proton magnetic resonance spectroscopy of late-life major depressive disorder. Psychiatry Res. 2009;172(3):210-4.

48. Sözeri-Varma G, Kalkan-Oğuzhanoglu N, Efe M, Kıroglu Y, Duman T. Neurochemical metabolites in prefrontal cortex in patients with mild/moderate levels in first-episode depression. Neuropsychiatr Dis Treat. 2013;9:1053.

49. Olvera RL, Caetano SC, Stanley JA, Chen H-H, Nicoletti M, Hatch JP, et al. Reduced medial prefrontal N-Acetyl-Aspartate levels in pediatric major depressive disorder: A multi-voxel in vivo1H spectroscopy study. Psychiatry Res. 2010;184(2):71-6.

50. Suriyajakryuththana W, Tuntiyatorn L, Teepprasarn N, Sukying C. Proton magnetic resonance spectroscopy in mild cognitive impairment and Alzheimer's disease: a preliminary study. J Med Assoc Thai. 2014;97(4):407-14.

51. Metastasio A, Rinaldi P, Mariani E, Feliziani F, Tarducci R, Gobbi R, et al., editors. Conversion of $\mathrm{MCl}$ to dementia: Role of proton magnetic resonance spectroscopy. International Psychogeriatrics. New York: Cambridge Univ Press; 2005.

52. Kantarci K, Weigand SD, Petersen RC, Boeve BF, Knopman DS, Gunter J, et al. Longitudinal $1 \mathrm{H}$ MRS changes in mild cognitive impairment and Alzheimer's disease. Neurobiol Aging. 2007;28(9):1330-9.

53. Wang Y, Jia Y, Xu G, Ling X, Liu S, Huang L. Frontal white matter biochemical abnormalities in first-episode, treatment-naive patients with major depressive disorder: a proton magnetic resonance spectroscopy study. J Affect Disord. 2012;136(3):620-6

54. Mao N, Fang J, Xie H, Liu X, Jiang X, Wang G, et al. Correlation between neurochemical metabolism and memory function in adolescent patients with depression: A multi-voxel $1 \mathrm{H}$ magnetic resonance spectroscopy study. Psychiatry Clin Neurosci. 2016;70(4):167-74.

55. Zhang $Y$, Han $Y$, Wang $Y$, Zhang $Y$, Li L, Jin E, et al. A MRS study of metabolic alterations in the frontal white matter of major depressive disorder patients with the treatment of SSRIs. BMC Psychiatry. 2015;15(1):99.

56. Murata T, Kimura H, Omori M, Kado H, Kosaka H, lidaka T, et al. MRI white matter hyperintensities, 1H-MR spectroscopy and cognitive function in geriatric depression: a comparison of early-and late-onset cases. Int J Geriatric Psychiatry. 2001;16(12):1129-35.

57. Phillips ML, Drevets WC, Rauch SL, Lane R. Neurobiology of emotion perception II: implications for major psychiatric disorders. Biol Psychiatry. 2003;54(5):515-28.

58. Ballmaier M, Toga AW, Blanton RE, Sowell ER, Lavretsky H, Peterson J, et al. Anterior cingulate, gyrus rectus, and orbitofrontal abnormalities in elderly depressed patients: an MRI-based parcellation of the prefrontal cortex. Am J Psychiatry. 2004;161(1):99-108.

59. Taylor WD, MacFall JR, Gerig G, Krishnan RR. Structusral integrity of the uncinate fasciculus in geriatric depression: Relationship with age of onset. Neuropsychiatr Dis Treat. 2007;3(5):669.

60. Wolk DA, Dickerson BC, Initiative ADN. Fractionating verbal episodic memory in Alzheimer's disease. Neuroimage. 2011;54(2):1530-9.

61. Irish M, Addis D, Hodges J, Piguet O. Considering the role of semantic memory in episodic future thinking: Evidence from semantic dementia. Brain. 2012;135(Pt 7):2178-91.

62. Defrancesco M, Egger K, Marksteiner J, Esterhammer R, Hinterhuber $H$, Deisenhammer EA, et al. Changes in white matter integrity before conversion from mild cognitive impairment to Alzheimer's disease. PloS one. 2014;9(8):e106062.

63. Han SD, Houston WS, Jak AJ, Eyler LT, Nagel BJ, Fleisher AS, et al. Verba paired-associate learning by APOE genotype in non-demented older adults: fMRI evidence of a right hemispheric compensatory response. Neurobiol Aging. 2007;28(2):238-47.

64. Erk S, Spottke A, Meisen A, Wagner M, Walter H, Jessen F. Evidence of neuronal compensation during episodic memory in subjective memory impairment. Arch Gen Psychiatry. 2011;68(8):845-52.

65. Petrella JR, Krishnan S, Slavin MJ, Tran T-TT, Murty L, Doraiswamy PM. Mild cognitive impairment: evaluation with 4-T functional MR imaging. Radiology. 2006;240(1):177-86.

66. Heun R, Freymann K, Erb M, Leube DT, Jessen F, Kircher T, et al. Mild cognitive impairment $(\mathrm{MCl})$ and actual retrieval performance affect cerebral activation in the elderly. Neurobiology of Aging. 2007;28(3):404-13.

67. Clément F, Belleville S, Mellah S. Functional neuroanatomy of the encoding and retrieval processes of verbal episodic memory in MCl. Cortex. 2010; 46(8):1005-15

68. Jin M, Pelak VS, Curran T, Nandy RR, Cordes D. A preliminary study of functional abnormalities in aMCl subjects during different episodic memory tasks. Magn Reson Imaging. 2012;30(4):459-70.
69. Clément F, Belleville S. Compensation and disease severity on the memoryrelated activations in mild cognitive impairment. Biol Psychiatry. 2010;68(10): 894-902.

70. Machulda MM, Senjem ML, Weigand SD, Smith GE, Ivnik RJ, Boeve BF, et al. Functional magnetic resonance imaging changes in amnestic and nonamnestic mild cognitive impairment during encoding and recognition tasks. J Int Neuropsychol Soc. 2009;15(3):372-82.

71. Giovanello KS, De Brigard F, Ford JH, Kaufer DI, Burke JR, Browndyke JN, et al. Event-related functional magnetic resonance imaging changes during relational retrieval in normal aging and amnestic mild cognitive impairment. I Int Neuropsychol Soc. 2012;18(5):886-97.

72. Bayram E, Caldwell JZ, Banks SJ. Current understanding of magnetic resonance imaging biomarkers and memory in Alzheimer's disease. Alzheimers Dement. 2018;4:395-413.

73. Jessen F, Block W, Träber F, Keller E, Flacke S, Papassotiropoulos A, et al. Proton MR spectroscopy detects a relative decrease of $\mathrm{N}$-acetylaspartate in the medial temporal lobe of patients with AD. Neurology. 2000;55(5):684-8.

74. Kantarci K, Smith GE, Ivnik RJ, Petersen RC, Boeve BF, Knopman DS, et al. 1 $\mathrm{H}$ magnetic resonance spectroscopy, cognitive function, and apolipoprotein E genotype in normal aging, mild cognitive impairment and Alzheimer's disease. J Int Neuropsychol Soc. 2002;8(7):934-42.

75. Pfefferbaum A, Adalsteinsson E, Spielman D, Sullivan EV, Lim KO. In vivo brain concentrations of $\mathrm{N}$-acetyl compounds, creatine, and choline in Alzheimer disease. Arch General Psychiatry. 1999;56(2):185-92.

76. Watanabe T, Shiino A, Akiguchi I. Hippocampal metabolites and memory performances in patients with amnestic mild cognitive impairment and Alzheimer's disease. Neurobiol Learn Mem. 2012;97(3):289-93.

\section{Publisher's Note}

Springer Nature remains neutral with regard to jurisdictional claims in published maps and institutional affiliations.

\section{Submit your manuscript to a SpringerOpen ${ }^{\circ}$ journal and benefit from:}

- Convenient online submission

- Rigorous peer review

- Open access: articles freely available online

High visibility within the field

- Retaining the copyright to your article

Submit your next manuscript at $\boldsymbol{\nabla}$ springeropen.com 